\title{
Feminismos interseccional e da reprodução social: rumo a uma ontologia integrativa ${ }^{1}$
}

\author{
Susan Ferguson ${ }^{2}$
}

Resumo: em sua busca por capturar a natureza contraditória e constituída por muitas camadas das subjetividades e das posições sociais através de uma perspectiva que insiste no caráter dinâmico e complexo do social, o feminismo interseccional tem inspirado as feministas marxistas a levar o feminismo da reprodução social para além da preocupação estreita das relações gênero/classe. Ainda assim, mesmo suas articulações politicamente mais radicais, não alcançam uma teorização completa da lógica integrativa que defendem. Esse artigo explora as raízes dessa teorização insuficiente, e sugere que ao compreender o social como constituído pela atividade humana prática cujo objeto (o mundo social e natural) é organizado de maneira capitalista, o feminismo da reprodução social ressalta a relação dialética entre o todo capitalista e suas diferentes partes. O desafio para o feminismo marxista é adotar esta abordagem dialética apoiando-se nos insights do feminismo intersec-cional para capturar de maneira mais convincente a unidade de um todo social complexo e diverso.

Palavras-chave: Teoria da reprodução social; Feminismo; Interseccional; Marxismo.

\footnotetext{
1 Em versão estendida, este artigo foi originalmente publicado em Historical Materialism, v. 24, n. 2, 2016. A adequação do texto para o Cadernos Cemarx foi feita pela própria autora. Tradução: Murillo van der Laan. Revisão: Mariana Shinohara Roncato e Rafael DiasToitio.

2 Professora Associada da Wilfrid Laurier University, Waterloo, Ontario, Canadá. E-mail: sferguson@wlu.ca.
} 


\begin{abstract}
: seeking to capture the multi-layered, contradictory, nature of subjectivities and social positions through a framework which insists upon the complex, dynamic nature of the social, intersectionality feminism has inspired Marxist-feminists to push social reproduction feminism beyond a narrow preoccupation with gender/class relations. Yet even its most politically radical articulations stop short of fully theorising the integrative logic they espouse. This article explores the roots of this under-theorisation, and suggests that in understanding the social as constituted by practical human activity whose object (the social and natural world) is organized capitalistically, social reproduction feminism highlights the dialectical relationship between the capitalist whole and its differentiated parts. The challenge for Marxist feminism is to embrace this dialectical approach while building on the insights of intersectionality feminism to more convincingly capture the unity of a complex diverse social whole.
\end{abstract}

Keywords: Social Reproduction Theory; Intersectionality Feminism; Marxism.

\title{
Introdução
}

As teorias feministas antirracistas e interseccionais evocam uma imagem inclusiva e integrativa do social, que tem inspirado muitas análises ricas e nuançadas de maneiras distintas, algumas vezes contraditórias, em que as relações de poder se tecem no interior e através das experiências cotidianas. Tal leitura complexa leva a teoria feminista muito além do essencialismo abstrato e das análises binárias. Não obstante, desde as primeiras formulações do feminismo interseccional, críticos e apoiadores questionaram a coerência do quadro teórico - apontando a dificuldade de teorizar as maneiras em que diferentes relações parciais de gênero, raça, sexualidade, e assim por diante, abrangem um todo integral unificado ${ }^{3}$.

${ }^{3}$ Ver Anthias, 2012; Davis, 2008; Dhamoon, 2011; Kerner, 2012; Nash, 2008; Simien and Hancock, 2011.

\begin{tabular}{l|l}
\hline 14 & Feminismos interseccional...
\end{tabular} 
Feministas que adotaram a perspectiva da reprodução social também se esforçaram para articular e explicar a experiência diferenciada-mas-unificada das múltiplas opressões. Elas inclinaram-se a conceituar o social de maneira estreita, frequentemente em termos estruturalistas que privilegiam as relações de gênero e de classe acima das outras ${ }^{4}$. Sem escusar essa resistência em teorizar relações como as de raça, de colonização e de queerness, quero voltar nossa atenção para o potencial do feminismo da reprodução social de ir além de suas limitações herdadas ${ }^{5}$. Sugiro que esse potencial do feminismo da reprodução social assenta-se na compreensão ampla e complexa do trabalho como uma "unidade concreta", uma categoria ontológica que captura - e uma experiência vivida que medeia e produz uma totalidade contraditória, histórica e ricamente diferenciada. Esse conceito multidimensional do trabalho (ou da atividade humana prática) convida a uma compreensão dialética do social que pode nos levar além da rigidez estreita das perspectivas estruturalistas sem esbarrar nos enigmas colocados pelo feminismo interseccional. Ele nos permite, em outras palavras, desenvolver uma teoria rigorosamente integrativa do social.

\section{Uma apreciação crítica do feminismo interseccional}

O feminismo interseccional distingue-se por seus esforços combinados para "lidar com a desorganização da subjetividade" (NASH, 2008, p. 4), como entende-se o que ocorre no interior de um campo complexo de relações sociais, nas quais cada e todo eixo de opressão converge com, e diverge de, todo outro eixo de opressão. Descritivamente flexível e profundamente ressonante, ele é frequentemente evocado como um "chavão" ou um "dispositivo

\footnotetext{
4 Ver Ferguson, 1999, 2008; Luxton, 2007; Luxton et al, 2014.

${ }^{5}$ Para diferentes abordagens racializando o feminismo da reprodução social ver Arat Koc, 2006; Bakker e Silvey, 2008; Ferguson e McNally, 2014; e Hennessey, 2013.
} 
heurístico" (DAVIS, 2008, p. 68). Ainda assim, sua ubiquidade não impediu suas críticas (em grande parte, dentro de suas próprias fileiras) de avançar um projeto atual de "explicação, questionamento e desenvolvimento"6 (ACKERLY e MCDERMOTT, 2012, p. 367), colocando indagações sobre sua coerência metodológica e ontológica: como identifica-se quais opressões são salientes e sob quais condições sociais? As opressões são melhores concebidas como identidades ou posições sociais? São as opressões irredutíveis, expressões dedistintas ontologias? Como, precisamente, os vários eixos de opressão se interseccionam? Há alguma força social que compele e molda essa interação? Se sim, qual é, e por quê?

De acordo com Yuval-Davis, respostas a essas questões caem em dois "campos"7 (YUVAL-DAVIS, 2006, p. 195). O primeiro adere a um modelo "aditivo" ou "cumulativo" no qual as opressões existentes interseccionam sob certas condições históricas para produzir um sujeito "que carrega um fardo múltiplo" (NASH, 2008, p. 6-7). Kimberlé Crenshaw pertence a esse "campo", retratando o social em termos espaciais, no qual, para usar seu exemplo, o cruzamento das ruas do colonialismo e do patriarcado representa um nó de múltiplas opressões. Identidades e experiências aqui emergem a partir dos espaços e tempos sócio-específicos que não podem ser explicados redutivamente por uma lógica singular e global (CRENSHAW, 1989). Antes de compreender suas diferentes dinâmicas opressivas e articular os meios e os objetivos de se resistir à opressão, se requer uma investigação sócio-histórica e um juízo politicamente informado.Uma abordagem como essa revela relações de poder que, de outro modo, estariam ocultas e pode - como sugeriram Crenshaw e suas co-editoras em um simpósio recente sobre feminismo interseccional - "criar uma conexão em torno de experiências

${ }^{6}$ Ver Davis, 2008, p. 75 para uma breve perspectiva sobre a literatura. Ver também Butler, 1990; Bannerji, 2005; McCall, 2005; Nash, 2008; Winker e Degele, 2011.

${ }^{7}$ Uso as aspas aqui para enfatizar que as integrantes de cada campo não inserem-se ou defendem rigidamente as distinções traçadas por Yuval-Davis.

\begin{tabular}{l|l}
\hline 16 & Feminismos interseccional...
\end{tabular} 
compartilhadas de discriminação, marginalização e privilégio" (CARBADO et al, 2013, p. 206).

Assim, a análise nesse "campo" tende a concentrar-se no nível micro, apresentando investigações empíricas que revelam quais relações opressivas estão em jogo, e como e por que elas exercem influência em um determinado momento sócio-histórico. Dinâmicas mais amplas informando a emergência e a atual reprodução sistêmica de relações opressivas não são geralmente reconhecidas ou examinadas. Perspectivas aditivas raramente se perguntam por que ou como as relações opressivas moldam as diferentes experiências e identidades nodais da maneira como o fazem - se há algo específico em seu posicionamento sócio-histórico que limita a variedade das possíveis configurações. Ao invés disso, Colonialismo e Patriarcarcado aparecem como independentes, pré-existentes, elementos trans-históricos da realidade, partes de um campo aparentemente abstrato que, de alguma forma, entram em contato um com o outro. Patriarcado e colonialismo podem se interseccionar, mas eles são concebidos como sistemas ontologicamente distintos ${ }^{8}$. Eles se combinam para criar uma realidade mais ampla, mas não são, eles mesmos, constitutivos e constituídos por essa realidade. A possibilidade de uma lógica sistêmica condicionando configurações particulares de experiências múltiplas de opressão simplesmente não é investigada.

Como conceituamos o social importa para o desenvolvimento de estratégias políticas efetivas. A totalidade social complexa e diferenciada avançada pelo feminismo interseccional sugere que uma política transformadora requer movimentos cruzados de solidariedade política - uma posição que é regularmente contraposta aos argumentos marxistas grosseiros, que demandam a priorização de uma política construída em uma concepção estreita de classe, que se sobrepõe às

\footnotetext{
${ }^{8}$ Ver Dhamoon, 2011, p. 233; Nash, 2008, p. 6-7; e Yuval-Davis, 2006, p. 197-198, para o desenvolvimento dessas críticas. Ver o argumento de Carbado et al, 2013, p. 308 para uma refutação parcial.
} 
políticas dos movimentos. Contudo, um modelo aditivo deixa de mostrar a necessidade lógica e histórica da solidariedade que apoia. Ao invés disso, pode contar apenas com apelos morais para que se respeite as diferenças e se reconheça "as experiências compartilhadas de discriminação". Um argumento mais convincente sobre a solidariedade demanda uma concepção de uma natureza diversa-masunificada do poder, uma que ilustre como as opressões, que algumas vezes contradizem umas às outras, também mantém sistematicamente um mundo não livre e punitivo. Ao explicar que os sujeitos oprimidos compartilham mais do que experiências de discriminação - que eles coletivamente constituem (e podem, portanto, coletivamente enfrentar) um conjunto abrangente de relações de poder -, uma robusta teoria do todo social desvela uma lógica sócio-material para solidariedade.

O segundo "campo" dentro do feminismo interseccional vai, de certa maneira, no sentido de uma teorização das relações de poder nesses termos. O modelo "constitutivo" propõe que raça, gênero, sexualidade e classe não existem previamente, em qualquer forma fixa, mas estão continuamente se reinventando em suas relações umas com as outras (YUVAL-DAVIS, 2006, p. 195). A imagem do enredamento no qual as distintas opressões habitam umas às outras suplanta as metáforas dos mapas das ruas, e o objetivo analítico muda de uma descrição da complexidade das experiências opressivas para a explicação de sua emergência, dinâmica e reprodução (YUVAL-DAVIS, 2006, p. 195). Ademais, alguns dentro desse "campo" concentram-se na totalidade social, ressaltando que o poder reside não apenas no interior das várias relações parciais, mas entre elas, evidenciando suas conexões integrais. "Sistemas distintos de opressão [...] são partes de uma estrutura global de dominação", escreve Patrícia Hill Collins, complementando que "cada sistema precisa dos outros para funcionar" (HILL COLLINS, 1990, p. 222).

Teorizar essas relações de poder mais abrangentes é uma prioridade para aqueles que tem como objetivo repolitizar um paradigma que tem sido desradicalizado pelo feminismo mainstream

\begin{tabular}{l|l}
\hline 18 & Feminismos interseccional...
\end{tabular} 
e acadêmico. Dhamoon, por exemplo, adverte contra a tendência a impor uma estabilidade categórica e reificar qualquer configuração particular das diferenças, insistindo em um foco "sobre o que a interação [entre práticas de generificação, racialização, etc.] revela sobre o poder" (DHAMOON, 2011, p. 234). De maneira semelhante, Floya Anthias insiste que qualquer movimento social está "inserido em relações de hierarquia no interior de uma multiplicidade de esferas situacionais e conjunturais específicas", e sugere que "lentes translocais" podem ressaltar o "panorama do poder" mais amplo sem perder de vista o contexto espacial e temporal imediato. Ela rejeita a noção de "sistemas" sociais ontologicamente distintos que "interseccionam" enquanto, não obstante, mantém uma compreensão da particularidade das opressões, insistindo que gênero, raça e outras relações são "salientes" ou tem "uma efetividade" em si mesmas, e por si mesmas, no interior desse panorama. Ao mesmo tempo, cada uma é "mutuamente interativa" e impossível de dissociar na realidade (ANTHIAS, 2012, p. 130).

Aqui, portanto, encontramos concepções abertas do social que parecem evitar as dificuldades da perspectiva aditiva. Gênero, raça e classe não são relações estáticas, pré-existentes no interior de um campo social abstrato, mas práticas e processos que herdamos, experienciamos e criamos no interior de uma constelação ampla de relações de poder. E o olhar analítico move-se entre os processos cotidianos nos quais, e através dos quais, reproduzimos a realidade e o contexto social mais amplo. Não obstante, a despeito de sua promessa, essa abordagem constitutiva também tem dificuldades para explicar a lógica social da relação entre as opressões particulares, interdependentes, e a totalidade social que integram. Essa totalidade é, em outras palavras, sub-teorizada.

Algumas, no interior do "campo" constitutivo simplesmente assumem como uma noção fragmentada dada do social na qual a raça pode estar "enredada" no gênero e na classe, mas é, em última instância, um sistema discreto (YUVAL-DAVIS, 1995, p. 195). É certo 
que as opressões são irredutíveis no sentido de que não são idênticas. Mas insistir simplesmente em sua irredutibilidade - sem postular ou explorar uma relação interna entre relações parciais e a totalidade social - é deixar de retornar essas categorias abstratas ao âmbito desordenado - mas-unificado da experiência9. Isso resulta, em outras palavras, em uma perspectiva unilateral e abstrata da realidade, tratando aquilo que é analiticamente discreto como realmente discreto.

Outras nesse "campo" veem as relações de poder mais amplas como compostas por configurações sempre variáveis de relações parciais, reproduzidas na ausência de qualquer lógica essencial ou sistêmica. Dhamoon, por exemplo, refere-se ao "quadro mais amplo no qual as diferenças são conectadas" como "representando o movimento mutável, desordenado, indeterminado, dinâmico e de múltiplas camadas da produção da diferença" (DHAMOON, 2011, p. 238-239, grifos meus). Anthias chega perto de nomear - e, assim, identificar a lógica social - das relações mais amplas em jogo. Advertindo contra uma "abordagem metodologicamente nacionalista", ela chama atenção para as maneiras nas quais as diferentes opressões estão situadas em um mundo geopolítico que é, ele mesmo, hierarquizado de acordo com uma lógica "translocal" (ANTHIAS, 2012, p. 130). Ainda assim, não é claro o que precisamente anima esse poder mais amplo. Seus leitores entendem apenas que abrange "campos sociais múltiplos e complexos [que pertencem] às facetas tanto materiais quanto discursiva das relações sociais". Esses campos são "conjunturais", e não produzem "nenhum resultado padrão" (ANTHIAS, 2012, p. 131; 133).

Bem entendido, a insistência na natureza mutável e aberta do todo social nos leva além da teoria social mecanicamente

\footnotetext{
${ }^{9}$ Bem entendido, não estou sugerindo que os sujeitos experienciam o mundo com qualquer tipo de coerência necessária. Suas experiências são unificadas, todavia, no sentido de que não experienciam, por exemplo, ser branca e mulher em um momento e espaço, e ser queer e expropriada, em outro. As diferenciações são significantes em nossas vidas, mas elas não são vividas separadamente.
}

\begin{tabular}{l|l}
\hline 20 & Feminismos interseccional...
\end{tabular} 
determinante e funcionalista. Mas por conceberem o poder como difuso e incognoscível, tais formulações podem apenas sinalizar uma lógica integrativa, afirmando sua existência sem nunca identificar as forças sociais realmente envolvidas. Como tais, essas formulações arriscam reproduzir aquilo que o feminismo interseccional pretende criticar: uma concepção fragmentada e textualizada da realidade ${ }^{10}$. E, apesar de o reconhecimento de relações de poder mais amplas parecer fundamentar o chamado por solidariedade política em uma lógica sócio-material, enquanto essas relações forem indeterminadas enquanto o todo social não exibir uma lógica sistêmica - esse chamado não tem necessariamente sujeitos ou direção. Somente quando uma dinâmica essencial integrativa é identificada como infletindo as diversas relações é que um potencial sujeito revolucionário pluralista é revelado e posicionado como o agente capaz de revirar as matrizes de poder entrelaçadas que o dominam.

\section{Dialética e determinação}

Uma perspectiva feminista que recusa do período anterior o reducionismo de sua lógica totalizante e de seu modo de teorizar tem, obviamente, seus atrativos. Mas é útil examinar mais de perto essa lógica antes de rejeitar qualquer possibilidade de dar conta de uma totalidade social determinante. A acusação de um reducionismo à classe econômica é apropriadamente levantada quando uma causalidade mecânica é invocada para explicar o mundo social em termos das atuações do capital. Nessa perspectiva, entende-se que as diferentes opressões existem porque (e são consideradas importantes na medida em que) elas são diretamente funcionais ao capitalismo. E "capitalismo" ou uma lógica de classe estreitamente definida são compreendidos como uma relação social discreta, com suas leis de

${ }^{10}$ Ver Davis, 2008. Também as "matrizes de produção de significado" de Dhamoon (2009) parecem considerar o poder primariamente em termos discursivos.

cadernos cemarx, no $10-2017 \quad 21$ 
movimento externamente impostas sobre todas as outras relações ${ }^{11}$. Um entendimento dialético da determinação, entretanto, não se ocupa da identificação de uma causalidade simples ou uma funcionalidade, e rejeita a noção de que o todo é externo às suas partes. Ao invés disso, analisa as maneiras pelas quais aspectos do social (que são, eles mesmos, reciprocamente determinados, ou co-constituídos) relacionam-se no interior de um contexto historicamente dado, com o objetivo de revelar a lógica subjacente que estrutura essas relações. Essa é a lógica que reside no todo. Isto é, ao mesmo tempo que relações parciais (de classe, gênero, raça, etc.) determinam ou constituem umas às outras e a totalidade social, essa última, por sua vez, exibe sua própria lógica de reprodução. E é essa lógica que estrutura ou determina - no sentido de exercer pressões reais e colocar limites reais sobre, mesmo se não as subsume completamente - todas as suas relações parciais constituintes (WILLIAMS, 1977, p. 83-89).

O social é, portanto, uma totalidade aberta e historicamente mutável, cuja lógica reprodutiva reside em todas as suas partes, mesmo se essas partes não são necessariamente ou puramente funcionais ou redutíveis ao todo. Relações sociais mais amplas, Himani Bannerji explica, "estão inseridas no desenho de toda sociedade em que vivemos. Elas informam [in-form] a formação social total, o que Marx chamou de 'modo de produção' que molda e modifica formas específicas de vida" (BANNERJI, 2014, p. 128). Esse é um todo (capitalista) unificado, mas um que é também diferenciado e contraditório. As distintas opressões não são redutíveis umas às outras, mas suas diferenças estão expressas no interior e através de (e algumas vezes excedendo) uma lógica compartilhada. Compreendida dialeticamente, portanto, uma narrativa totalizante não exclui reconhecer, entender e explicar a diferença entre suas partes constitutivas, e a co-constituição no interior de um processo total. Ela assume essas partes como integrais à reprodução social do todo, um todo que somente se constitui no

\footnotetext{
${ }^{11}$ Ver McNally, 2015.
}

\begin{tabular}{l|l}
\hline 22 & Feminismos interseccional...
\end{tabular} 
interior, e através, da história concreta e real. "Capitalismo" como uma simples abstração não existe "realmente". Há apenas o capitalismo racializado, patriarcal ${ }^{12}$, no qual a classe é concebida como uma unidade de relações diversas que produzem não apenas lucro ou capital, mas o capitalismo ${ }^{13}$. Apesar de podermos (e precisarmos) pensar sobre relações discretas para entender a diferença, elas são distintas apenas abstratamente, no pensamento. Uma teoria integrativa é incompleta a menos que ela se mova dessa abstração para nomear a lógica social que informa a unidade existente, concreta, dessas relações.

O feminismo interseccional simplesmente não diferencia entre concepções dialéticas e não dialéticas de determinação e totalidade, levando seus proponentes a descartar ou sub-teorizar a lógica integrativa da totalidade social. Ambos os "campos" resistem em atribuir qualquer princípio sistêmico organizador a um todo social mais amplo: opressões se interseccionam e residem umas nas outras, mas elas o fazem, aparentemente, de maneira aleatória, sem qualquer lógica necessária. Explicar como e por que experiências diversas se interconectam de determinadas maneiras e não de outras não é apenas uma tarefa histórica, como alguns presumem ${ }^{14}$. É também teórica e envolve abandonar a aritmética e, ao invés disso, conceber o todo social como algo maior do que a soma de suas partes. Somente quando podemos apreender e nomear a lógica social e o dinamismo da totalidade, é que podemos entender como ou por que suas partes são mutuamente constituídas de maneiras que regularmente reproduzem certas relações e padrões sociais ou tendências, e regularmente excluem outras.

\footnotetext{
${ }^{12}$ Obviamente essa lista é parcial.

${ }^{13}$ Como McNally (2015, p. 135-136) explica: enquanto “determinações particulares são [...] apreendidas como constitutivas do todo do qual são partes [...] o todo é entendido como vazio e sem vida quando considerado abstraindo suas partes".

${ }^{14}$ Ver, por exemplo, Nash, 2008, p. 13. E eu considero ser isso o que Anthias (2012, p. 131) quer dizer ao propor que relações de poder mais amplas são "conjunturais".
} 


\section{Teorizando relações integrais: feminismo da reprodução social}

O feminismo da reprodução social fornece um caminho promissor para teorizar a unidade integral das relações sociais, diversas e diferenciadas, que o feminismo interseccional ressalta. Em seu núcleo está a concepção de trabalho como amplamente produtivo - criador não apenas de valores econômicos, mas da sociedade (e, portanto, da vida) mesma. Ele abrange "as atividades e atitudes, comportamentos e emoções, responsabilidades e relações diretamente envolvidas na manutenção diária e intergeracional da vida" (LASLETT e BRENNER, 1989, p. 382). Esse não é o "trabalho" como tem sido entendido pela economia mainstream e pelo marxismo vulgar. É, na verdade, a "atividade humana prática" que cria todas as coisas, práticas, pessoas, relações e ideias que constituem a totalidade social mais ampla - aquilo que Marx e Engels identificaram como “a primeira premissa de toda a história humana" (MARX, 1964, p. 111; MARX e ENGELS, 1932). Ao partilharmos da atividade prática humana nós (todos) partilhamos da realidade mais ampla - tanto no sentido de expressar essa realidade, quanto no de ajudar a recriá-la. Trabalho - considerado de maneira ampla - é a premissa ontológica de uma unidade integrada (embora diversa). E a despeito desse significado não ter sido sempre evidente para as feministas da reprodução social, esse paradigma nos equipa com os conceitos e a linguagem necessários para torna-lo evidente ${ }^{15}$.

Ao começar com uma noção ampliada do trabalho, o feminismo da reprodução social não está simplesmente valorizando aquelas

\footnotetext{
${ }^{15}$ Marx usa o termo reprodução social para se referir à regeneração global do capitalismo: às instituições e processos que permitem que as relações "produtivas" prosperem, assim como às próprias relações diretas de produção. As feministas da reprodução social tendem a usar o termo para se referir apenas àqueles processos fora das relações diretas de produção que são necessários para a sobrevivência do capitalismo (em termos gerais, a reprodução diária geracional dos trabalhadores). Meu uso se movimenta entre os dois significados, mas busca uma maior precisão através de adjetivações como "global" ou "total" quando se refere ao uso marxiano.
}

\begin{tabular}{l|l}
\hline 24 & Feminismos interseccional...
\end{tabular} 
atividades e relações que até então haviam sido naturalizadas e amplamente negligenciadas. Ele está - e isto é crucial - avançando um argumento sobre a relação interna entre trabalho reprodutivo e produtivo. Esse argumento foi articulado inicialmente por Lise Vogel em seu livro Marxism and the Oppression of Women: Toward a Unitary Theory, de 1983. Vogel insiste que a família da classe trabalhadora não é apenas o local predominante da reprodução da força de trabalho, mas também que é a natureza interdependente (a despeito de contraditória) da relação entre o âmbito doméstico e o local de trabalho que garante que a opressão da mulher sob o capitalismo persistirá. A opressão das mulheres "gira em torno do significado social do trabalho doméstico para o capital - o fato de que a produção e a reprodução da força de trabalho é uma condição essencial que sustenta a dinâmica do sistema capitalista, tornando possível para o capitalismo reproduzir a si mesmo" (FERGUSON e MCNALLY, 2013, p. xxv). A manutenção do poder social capitalista, assim, articula-se com as buscas por maneiras de regular a reprodução social no geral, e as capacidades biofísicas das mulheres de reproduzir a próxima geração, no particular ${ }^{16}$.

Isso não é um argumento funcionalista: a necessidade que o capital tem da reprodução social do trabalho não precisa da forma familiar e da opressão das mulheres (no sentido de causar o seu vir a ser). Em um nível, o capital é agnóstico sobre como "obtém" o trabalho que explora. Assim, outras formas de reprodução social (campos de trabalho forçado, escravidão, migração, prisões) estão disponíveis a ele, ou podem ser imaginadas. Mas a existência das necessidades do capital explica porque uma instituição altamente efetiva - o âmbito doméstico privatizado - é alardeada e reforçada (através de uma legislação machista, sistemas educacionais, práticas de seguridade social, por exemplo), e, desse modo, enraizada nas sociedades capitalistas (por mais que se tenha herdado práticas das sociedades précapitalistas e as remoldado ao longo do tempo). É essa relação essencial

${ }^{16}$ Ver Luxton, 2006. 
entre as necessidades produtivas e reprodutivas da formação social capitalista, e não um impulso patriarcal trans-histórico, portanto, que torna a opressão das mulheres possível e provável sob o capitalismo.

As feministas da reprodução social posteriores desenvolveram e expandiram esse insight, explorando o papel do Estado na manutenção e complementação da família ${ }^{17}$. Por demonstrar que o Estado, o âmbito doméstico e o mercado são integralmente ligados (de maneira contraditória, mas necessária), o feminismo da reprodução social é um poderoso quadro analítico que evita as dificuldades da perspectiva aditiva. Ele nos leva muito além das meras descrições da realidade, no sentido de identificar e explicar as maneiras pelas quais a totalidade capitalista inflete nossas instituições, interações e relações e por que práticas alternativas que desafiam as prioridades capitalistas são difíceis de se manterem. A lógica capitalista é determinante no sentido dialético da palavra: a lógica de acumulação e expropriação demanda certas relações de gênero e outras não, mesmo se essas relações podem exceder tal lógica. Ao mesmo tempo, essas relações de gênero - reciprocamente determinantes de, e determinadas por, relações raciais e outras ainda - constituem o capitalismo. Elas estão entre as forças sociais reais, a realidade vivida, através da qual a lógica de acumulação e expropriação opera.

Marx também inicia com uma concepção compreensiva de trabalho ou "da atividade humana prática" em sua análise do capitalismo. Todavia, ainda que ele insista que tal atividade é sempre, e em todos os lugares, enraizada no social - "toda produção é apropriação da natureza pelo indivíduo no interior e através de uma forma determinada de sociedade" (MARX, 1973, p. 29) - ele avança na exploração da socialidade sistêmica de apenas uma forma de trabalho, aquele realizado para o capital. Observando a relação essencial desse último com o capital, ele ignora em grande medida o papel do trabalho reprodutivo no interior da reprodução total do capital, tratando-o

\footnotetext{
${ }^{17}$ Ver, por exemplo, Piccio, 1992.
}

\begin{tabular}{l|l}
\hline 26 & Feminismos interseccional...
\end{tabular} 
como uma consequência natural do "impulso do trabalhador para sua autopreservação e propagação" (MARX, 1976, p. 275; p. 716). A rica diversidade do trabalho e dos corpos que trabalham é, desse modo, marginalizada na teoria de Marx sobre o capitalismo. O feminismo da reprodução social restaura essa diversidade, desenvolvendo o aparato conceitual para compreender o trabalho como uma experiência diferenciada-mas-compartilhada, uma unidade diversa, concreta.

Esse avanço teórico articula a identificação não somente de formas diferentes de trabalho, mas enfatiza e problematiza a conexão de diferentes formas de trabalho e diferentes corpos: se queremos dar conta da natureza do processo através do qual a sociedade é reproduzida, especialmente geracionalmente reproduzida, precisamos estar atentos ao fato de que o trabalho é uma experiência concreta, corporificada. Diferenças biofísicas entre indivíduos sexuados masculinos e femininos são, portanto, de imensa importância. Esse não é um argumento biologicamente determinista. Essas diferenças subsistem no interior de uma "forma determinada de sociedade" que é caracterizada pelo modo capitalista de produção. Esse, por sua vez, avança a regulação do trabalho reprodutivo sobre o qual a reprodução contínua do capital depende. Essa distinção biológica um tanto crua é compreendida socialmente no interior e através de relações de gênero específicas, que tendem a manter ou reforçar a dependência do capital de processos reprodutivos privados, precisamente por conta da dominação global do capital sobre o social.

Essa dominação é assegurada porque nós devemos trabalhar para reproduzirmos nós mesmos e o mundo, mas não podemos acessar livremente os meios dessa reprodução: o capital expropriou a vasta maioria de nós dos meios de nossa subsistência, assim como dos meios de produzi-la. Como resultado, tudo que nós fazemos para reproduzir o mundo é necessariamente condicionado pelas necessidades do capital. Ainda assim a dominação desse, não é absoluta. Precisamente porque as pessoas retêm algum controle sobre a sua reprodução social e biofísica, outros interesses e dinâmicas relacionais podem rivalizar, 
e de fato o fazem, com o imperativo capitalista. Lutas pelo acesso ao aborto, creches e cuidados às crianças, melhores salários, água potável, por exemplo, remodelam as relações entre trabalhadores e capital, e entre os próprios trabalhadores. Se são bem sucedidas, elas desfalcam as formas patriarcais de relações, e outras ainda; se elas falham, tendem a reforçar tais relações. O que permanece notavelmente constante no capitalismo, entretanto, é a relegação da reprodução à esfera privada e a concomitante regulação dos corpos das mulheres que ela engendra. A despeito do capitalismo não ter "criado" a opressão da mulher, ele certamente fornece as condições sócio-materiais e a razão para mantê-la (de formas historicamente distintas e mutáveis, entretanto).

É claro que os corpos que trabalham não são apenas diferentemente sexuados e generificados ${ }^{18}$. Eles também são diferentemente racializados. Mas porque a racialização, diferentemente da generificação, não pode ser nem mesmo parcialmente explicada em termos de diferenças biológicas ou genéticas, precisamos considerar o que mais pode ser relevante sobre os corpos que trabalham para desvelar a relação entre capitalismo e racismo (MILES, 1989, p. 70). Com muito desse trabalho ainda a ser feito, ofereço aqui apenas comentários provisórios. Como sugeri em outro lugar, parece útil pensar que os corpos que trabalham não são apenas diferentemente sexuados, eles também são diferentemente especializados em sentido tanto geográfico como social ${ }^{19}$. Todos nós nascemos e trabalhamos para reproduzir o mundo em locais sócio-históricos e geográficos específicos. E a despeito de abstratamente tais diferenças terem poucas consequências, elas são de grande importância concretamente porque esses locais são alcançados de maneira desigual pela desigual dinâmica sempre expansiva do capitalismo. Dependendo de quais espaços os diferentes corpos ocupam no interior desse sistema mundial

\footnotetext{
${ }^{18}$ Sem mencionar as diferenças de sexualidade, idade, capacidade, e assim por diante.

${ }^{19}$ Katz, 2001; ver também Ferguson, 2008.
}

\begin{tabular}{l|l}
\hline 28 & Feminismos interseccional...
\end{tabular} 
hierárquico, eles têm um maior ou menor acesso à educação, assistência médica, mobilidade, aos locais de trabalho seguros e transporte até os mesmos, aos direitos básicos e liberdades. Como resultado, o trabalho e as vidas das pessoas são valorados de maneira diferente no interior do capitalismo desde o começo - as relações capitalistas se aproveitam e ajudam a reproduzir e remodelar essas diferenças em grande parte através de meios políticos, econômicos e sociais de racialização e racismo. Nos níveis locais, nacionais e internacionais, o Estado ajuda a administrar essa reprodução e remoldá-la. Políticas de imigração, cidadania e outras, apoiadas pelo poder policial e militar, operacionalizam e legitimam práticas racializadas de inclusão e exclusão baseadas precisamente nos diferentes espaços geográficos e sociais ocupados. Em outras palavras, o local sócio-geográfico dos corpos - e o trabalho envolvido em reproduzir socialmente esses corpos - importa: corpos iguais se tornam diferentes, e diferentemente valorados, no interior das sociedades capitalistas. Discursos e práticas de racialização e de racismo existentes são remoldados para ajudar a justificar e sistematizar essa desigualdade, assim como novos discursos e práticas são inventadas ${ }^{20}$.

O argumento aqui não é apenas que o racismo simplesmente responde diretamente à necessidade do capital de uma diferenciação do mercado de trabalho. Assim como no caso das relações de gênero, as lutas das pessoas para controlar as condições de sua própria reprodução podem alterar, e de fato o fazem, as relações raciais ${ }^{21}$. Comunidades imigrantes ou racializadas podem conquistar melhor iluminação, moradia e transporte, e os protestos nas ruas podem levar a tais mudanças nas políticas. Tais conquistas (que são frequentemente

${ }^{20}$ Ver Ferguson e McNally, 2014. Ver também Farris, 2017; Arat-Koc, 2006; Glenn, 1992; e Colen, 1995. Processos de desumanização envolvem também dinâmicas psico-sociais complexas. Para uma discussão sobre a constituição psico-social de capitalismo, ver Hennessey, 2013; Wright, 2006; e Palmer, 1989.

${ }^{21}$ Bem entendido, a questão aqui não é sobre a origem do racismo, mas sua reprodução atual. 
mudanças graduais nas diferenciações espaciais e sociais) podem levar a mudanças políticas e regulatórias que respeitam de maneira mais justa a vida humana e a dignidade, alterando, desse modo, as relações raciais. Mas o fato de que nossos meios de reprodução social são organizados de maneira capitalista - que os trabalhadores não possuem acesso direto e comunal à moradia, subsistência, assistência médica, e assim por diante - colocam limites definitivos a essas mudanças. Esses limites são vistos por alguns marxistas como evidências da necessidade de subsumir as lutas raciais e de gênero às lutas de "classes". Mas uma abordagem do feminismo da reprodução social enfatiza e insiste no oposto: que a conexão interna entre produção e reprodução torna tais lutas integrais à luta de classes.

\section{Por que uma formação social capitalista?}

Ao considerar o trabalho como corporificado, como uma prática espacialmente localizada sustentando a reprodução da totalidade social, o feminismo da reprodução social oferece uma concepção teoricamente rica do trabalho como uma unidade diversa. É diversa em sua natureza generificada, racializada, sexualizada (e assim por diante). Mas o trabalho (re)produtivo (ou atividade humana prática) é também um momento unificador, na medida em que todo corpo que trabalha, diversamente constituído, participa na reprodução de uma realidade social compartilhada, e é uma expressão desse todo social. Esse insight nos coloca em uma posição ontológica diferente daquela do feminismo interseccional - uma que evita uma lógica aditiva e conceituações indeterminadas de poder e oferece uma representação mais complexa e concreta do social. Nessa perspectiva, "relações que são internas umas às outras [...] de maneira que quando uma importante se modifica, o fator mesmo se altera" (OLLMAN, 1971). Em outras palavras, tudo é socialmente mediado. Não há trabalho fora do gênero, raça ou capacidade, assim como não há gênero fora da raça, do trabalho e da sexualidade. Mesmo que muitas feministas

\begin{tabular}{l|l}
\hline 30 & Feminismos interseccional...
\end{tabular} 
interseccionais pudessem concordar com tal afirmação, a perspectiva do feminismo da reprodução social completa a jornada dialética ao identificar a lógica capitalista no interior e através da qual as partes do todo são integradas.

Dizer que a totalidade social é uma totalidade social capitalista é sugerir que a lógica e os imperativos da acumulação e da produção que sobrepõem o lucro à necessidade - um conjunto específico de relações sociais entre muitas - dominam (no sentido de exercer pressões sobre e um conjunto de poderosos limites todos os aspectos da reprodução social). Essa dominação resulta de um processo histórico marcado por cercamentos, escravidão, caça às bruxas e pogroms, assim como revoluções políticas, por meio dos quais o trabalho que produz os meios de produção e subsistência é expropriado e organizado de maneira capitalista. As relações sociais capitalistas desempenham um papel crucial ao moldar os meios e os processos através dos quais as pessoas organizam suas vidas fora da relação econômica específica entre trabalho assalariado/capital porque 1) a vasta maioria das pessoas não pode subsistir exceto através da venda de seu trabalho ao capital ou de outras formas de dependência do mercado; 2) o lucro capitalista e a acumulação são decisivamente dependentes da disponibilidade de trabalhadores assalariados "livres" para essa exploração ${ }^{22}$. A despeito do trabalho social reprodutivo ser (em diferentes graus) parcialmente autônomo frente à dominação do capital, não há trabalho na sociedade moderna inteiramente fora do capital, e não há capital fora do trabalho ${ }^{23}$ (socialmente diferenciado [re]produtivo). Vemos a relação estruturante do capital com a reprodução social, na medida em que esses processos

\footnotetext{
${ }^{22}$ Não obstante ser crucial, a dependência do capital do trabalho "livre" não é, obviamente, absoluta. O capital depende também do trabalho não-livre e a distinção entre essas duas formas de trabalho pode ser facilmente ofuscada.

${ }^{23}$ Em outras palavras, nem todo trabalho produtivo é organizado de maneira capitalista. Economias de subsistência podem ser encontradas em toda parte do mundo. Mas mesmo estas são condicionadas por relações capitalistas: precisamente porque as relações capitalistas são globalmente dominantes, as economias de subsistência estão necessariamente atadas a partir de um status subalterno.
} 
são supridos pelo mercado através de bens aos consumidores, que frequentemente são acessados através de rendimentos derivados do mercado que são obtidos por um ou mais membros de um domicílio ${ }^{24}$. Isto é, assim como o capital necessita de um processo (privatizado) de reprodução social, esse processo de reprodução necessita do capital. Pessoas podem encontrar soluções criativas, não mercadorizadas, para suas necessidades reprodutivas sociais, assim como formas comunais de vida, incluindo cooperativas, e assim por diante. Mas essas são exceções que, por seu caráter marginal, provam a regra - maneiras de literalmente "se virar" ou de "sobreviver" compelidas pelo fato de que os meios de vida não são possuídos comunalmente, mas monopolizados pelos proprietários do capital.

Falar de um todo social que é dominado pela dinâmica capitalista não é dizer que o imperativo capitalista é absoluto. Os imperativos da vida, da reprodução social, não apenas regularmente o excedem, eles são também organizados por, e através de, outras formas de relações sociais, algumas anteriores ao capitalismo ${ }^{25}$. Mas o imperativo capitalista é, não obstante, determinante no sentido de que impõe pressões e limites, de maneira que apenas certas relações e processos (e não outros) "fazem sentido", e são reforçadas e sancionadas socialmente (no direito, na prática institucional e na representação simbólica) e individualmente, mesmo se elas também são sempre contestadas.

Disso seguem-se duas lições políticas fundamentais. A primeira é que construir novas possibilidades genuínas, que melhor se alinham com a liberdade humana, demanda transformar as fundações sóciomateriais sobre as quais produzimos e reproduzimos o mundo. Isso significa romper com o impulso capitalista de privatizar

\footnotetext{
${ }^{24}$ Ver Genevieve Lebaron (2010) sobre a atual reestruturação dessa relação a modelos neoliberais de acumulação do capital.

${ }^{25}$ Todas as opressões anteriores, entretanto, são reorganizadas no interior do modo capitalista de produção.
}

\begin{tabular}{l|l}
\hline 32 & Feminismos interseccional...
\end{tabular} 
a reprodução social, e (re)apropriar e (re)coletivizar os meios de subsistência para todos. A segunda é que, se as relações sociais se relacionam internamente, uma mudança em uma altera todas as outras. Assim, não há nenhuma razão convincente para se priorizar lutas econômicas estreitas ou baseadas no local de trabalho na luta por uma sociedade melhor. Qualquer luta no interior do reino da reprodução social que coloque as necessidades humanas acima dos interesses do capital - seja anti-racista, feminista, anti-colonial, ou por educação, saúde e transporte - pode afetar a formação social capitalista. Na medida em que são ressaltadas politicamente as relações internas de todas as opressões, umas com as outras e com a totalidade capitalista, tais lutas podem fazer avançar a consciência de classe $^{26}$ (em oposição àquela setorial). E, na medida em que essas lutas são bem sucedidas, e o capital (geralmente através do Estado) é forçado a assumir uma maior responsabilidade pelos custos de sua reprodução, as fundações sócio-materiais da opressão e da exploração serão enfraquecidas. Obviamente, a relação trabalho assalariado/capital deve, em última análise, ser subvertida se se quer pôr um fim à dinâmica capitalista que domina a reprodução social. Isso não requere, entretanto, uma priorização das lutas nos locais de trabalho frente às demais. Coloca-se, simplesmente, uma ênfase na tarefa de encontrar maneiras de se construir uma solidariedade significativa que conecte as lutas anti-racistas, feministas e todas aquelas voltadas à reprodução social às resistências baseadas no local de trabalho - uma solidariedade que assenta-se não apenas nos apelos ao respeito às diferenças, mas na lógica sócio-material compulsória que mostra como as relações opressivas moldam, e são moldadas, pela totalidade social que compõem.

${ }^{26}$ Ver McNally, 2015, p. 142-144. 


\section{Referências bibliográficas}

ACKERLY, B. e MCDERMOTT, R. 'Introduction. Recent Developments in Intersectionality Research: Expanding beyond Race and Gender'. Politics \& Gender, n. 8, p. 367-370, 2012.

ANTHIAS, F. Hierarchies of Social Location, Class and Intersectionality: Towards a Translocational Frame. International Sociology, vol. 28, n. 1, p. 121-38, 2012.

ARAT-KOC, S. Whose Social Reproduction? Transnational Motherhood and Challenges to Feminist Political Economy. In: BEZANSON, K. e LUXTON, M. (org.). Social Reproduction: Feminist Political Economy Challenges Neo-Liberalism. Montreal: McGill-Queen's University Press, 2006.

BAKKER, I. e SILVEY, R. (org.). Beyond States and Markets: The Challenges of Social Reproduction. Nova York: Routledge, 2008.

BANNERJI, H. Building from Marx: Reflections on Class and Race. Social Justice, v. 32, n. 4, p. 144-60, 2005.

Marxism and Anti-Racism in Theory and Practice: Reflections and Interpretations. In: BAKAN, A. B. e DUA, E. (org.). Theorizing Anti-Racism: Linkages in Marxism and Critical Race Theories. Toronto: University of Toronto Press, 2014.

BUTLER, J. Gender Trouble: Feminism and the Subversion of Identity. Nova York: Routledge, 1990.

CARBADO, D. et al. Intersectionality: Mapping the Movements of a Theory. Du Bois Review, v. 10, n. 2, p. 303-12, 2013.

\begin{tabular}{l|l}
\hline 34 & Feminismos interseccional...
\end{tabular} 
COLEN, S. "Like a Mother to Them": Stratified Reproduction and West Indian Childcare Workers and Employers in New York. In: GINSBURG, F. D. e RAPP, R. Conceiving the New World Order: The Global Politics of Reproduction. Berkeley: University of California Press, 1995.

CRENSHAW, K. Demarginalizing the Intersection of Race and Sex: A Black Feminist Critique of Antidiscrimination Doctrine, Feminist Theory, and Antiracist Politics. Chicago: University of Chicago Legal Forum, 1989.

DAVIS, K. Intersectionality as Buzzword: A Sociology of Science Perspective on What Makes a Feminist Theory Successful. Feminist Theory, v. 9, n. 1, p. 67-85, 2008.

DHAMOON, R. K. Considerations on Mainstreaming Intersectionality. Political Research Quarterly, v. 64, n. 1, p. 230-43, 2011.

FARRIS, S. In the Name of Women's Rights: The Rise of Femonationalism. Durham: Duke University Press, 2017.

FERGUSON, S. Building on the Strengths of the Socialist Feminism Tradition. Critical Sociology, v. 25, n. 1, p. 1-15, 1999.

. Canadian Contributions to Social Reproduction Feminism: Race and Embodied Labor. Race, Gender, Class, v. 15, n. 1-2, p. 42-57, 2008.

. MCNALLY, D. Capital, Labour-power, and Gender-relations: Introduction to the Historical Materialism Edition of Marxism and the Oppression of Women. In: VOGEL, L. Marxism and the Oppression of Women: Toward a Unitary Theory. London: Brill, 2013. 
Precarious Migrants: Gender, Race and the Social Reproduction of a Global Working Class. In: PANITCH, L. e ALBO, G. (org.). Socialist Register 2015: Transforming Classes. Londres: Merlin Press, 2014.

GLENN, E. N. From Servitude to Service Work: Historical Continuities in the Racial Division of Paid Reproductive Labor. Signs, v. 18, n. 1, p. 1-43, 1992.

HENNESSEY, R. Fires on the Border: The Passionate Politics of Labor Organizing on the Mexican Frontera. Minneapolis: University of Minnesota Press, 2013.

HILL COLLINS, P. Black Feminist Thought : Knowledge, Consciousness, and the Politics of Empowerment. Nova York: Routledge, 1990.

HONTAGNEU-SOTELO, P. e AVILLA, E. "I'm here, but I'm there": The Meanings of Latina Transnational Motherhood. In: ZINN, M. B. et al. (org.). Gender Through the Prism of Difference. Boston: Allyn and Bacon, 2000.

KATZ, C. Vagabond Capitalism and the Necessity of Social Reproduction. Antipode, n. 33, p. 709-38, 2001.

KERNER, I. Questions of Intersectionality: Reflections on the Current Debate. European Journal of Women's Studies, v. 19, n. 2, p. 203-18, 2012.

LASLETT, B. e BRENNER, J. Gender and Social Reproduction: Historical Perspectives. Annual Review of Sociology, n. 15, p. 381-404, 1989.

\begin{tabular}{l|l}
\hline 36 & Feminismos interseccional...
\end{tabular} 
LEBARON, G. The Political Economy of the Household: Neoliberal Restructuring, Enclosures, and Daily Life. Review of International Political Economy, v. 17, n. 5, p. 889-912, 2010.

LUXTON, M. Feminist Political Economy in Canada and the Politics of Social Reproduction. In: BEZANSON, K. e LUXTON, M. Social Reproduction: Feminist Political Economy Challenges Neo-Liberalism. Montreal: McGill-Queen's University Press, 2006.

. Alternatives Forum: Reclaiming Marxist Feminism. Studies in Political Economy, n. 94, p. 135-84, 2014.

MCCALL, L. The Complexity of Intersectionality. Signs, v. 30, n. 3, p. 1771-800, 2005.

MCNALLY, D. The Dialectics of Unity and Difference in the Constitution of Wage-labour: On Internal Relations and Working Class Formation. Capital \& Class, v. 39, n. 1, p. 131-46, 2015.

MARX, K. [1844]. The Economic \& Philosophic Manuscripts or 1844. Nova York: International Publishers, 1964.

[1857-61]. Grundrisse. 1973. Disponível em: <http://www. marxists.org/archive/marx/works/download/Marx_Grundrisse. $\operatorname{pdf}>$.

; ENGELS, F. [1932]. The German Ideology. Disponível em: <http:// www.marxists.org/archive/marx/works/1845/german-ideology/ index.htm>.

MILES, R. Racism. Londres: Routledge, 1989.

cadernos cemarx, $\mathrm{n}^{\mathrm{0}} 10-2017 \quad 37$ 
NASH, J. C. Re-thinking Intersectionality. Feminist Review, n. 89, p. 1-15, 2008.

OLLMAN, B. [1971]. Alienation: Marx's Conception of Man in Capitalist Society. Disponível em: <www.dialecticalmarxism.com>.

PALMER, P. Domesticity and Dirt: Housewives and Domestic Servants in the United States, 1920-1945. Filadélfia: Temple University Press, 1989.

PICCHIO, A. Social Reproduction: The Political Economy of the Labour Market. Cambridge: Cambridge University Press, 1992.

SIMIEN, E. M. e HANCOCK, A-M. Mini-Symposium: Intersectionality Research. Political Research Quarterly, v. 64, n. 1, p. 185-86, 2011.

VOGEL, L. Marxism and the Oppression of Women: Toward a Unitary Theory. Londres: Pluto, 1983.

WILLIAMS, R. Marxism and Literature. Oxford: Oxford University Press, 1977.

WINKER, G. e DEGELE, N. Intersectionality as Multi-level Analysis: Dealing with Social Inequality. European Journal of Women's Studies, v. 18, n. 1, p. 51-66, 2011.

WRIGHT, M. Disposable Women and other Myths of Global Capitalism. Nova York: Routledge, 2006.

YUVAL-DAVIS, N. Intersectionality and Feminist Politics. European Journal of Women's Studies, v. 13, n. 3, p. 193-209, 2006.

\begin{tabular}{l|l}
\hline 38 & Feminismos interseccional...
\end{tabular} 